\title{
Author Correction: Decoupling electron and ion storage and the path from interfacial storage to artificial electrodes
}

Chia-Chin Chen and Joachim Maier (D)

Correction to: Nature Energy https://doi.org/10.1038/s41560-017-0084-x, published online 5 February 2018.

In the version of this Perspective originally published, in the sentence "It is worthy of note that the final LiF-free situation characterized by $\mathrm{MnO}$ taking up the holes and the ( $\mathrm{F}^{-}$containing) $\mathrm{MnO}$ surface taking up the lithium ions is also a subcase of the job-sharing concept $^{23}$ ", the word 'holes' should have been 'electrons'. This has now been corrected.

Published online: 23 April 2018

https://doi.org/10.1038/s41560-018-0154-8 